\title{
Collaborative learning
}

Citation for published version (APA):

Goncalves Pires, E. M. S., Daniel-Filho, D. A., de Nooijer, J., \& Dolmans, D. H. J. M. (2020). Collaborative learning: Elements encouraging and hindering deep approach to learning and use of elaboration strategies. Medical Teacher, 42(11), 1261-1269. https://doi.org/10.1080/0142159x.2020.1801996

\section{Document status and date:}

Published: 01/11/2020

DOI:

10.1080/0142159x.2020.1801996

Document Version:

Publisher's PDF, also known as Version of record

\section{Document license:}

Taverne

\section{Please check the document version of this publication:}

- A submitted manuscript is the version of the article upon submission and before peer-review. There can be important differences between the submitted version and the official published version of record.

People interested in the research are advised to contact the author for the final version of the publication, or visit the DOI to the publisher's website.

- The final author version and the galley proof are versions of the publication after peer review.

- The final published version features the final layout of the paper including the volume, issue and page numbers.

Link to publication

\footnotetext{
General rights Owners
rights.

- You may freely distribute the URL identifying the publication in the public portal. please follow below link for the End User Agreement:

www.umlib.nl/taverne-license

Take down policy

If you believe that this document breaches copyright please contact us at:

repository@maastrichtuniversity.nl

providing details and we will investigate your claim.
}

Copyright and moral rights for the publications made accessible in the public portal are retained by the authors and/or other copyright owners and it is a condition of accessing publications that users recognise and abide by the legal requirements associated with these

- Users may download and print one copy of any publication from the public portal for the purpose of private study or research.

- You may not further distribute the material or use it for any profit-making activity or commercial gain

If the publication is distributed under the terms of Article $25 \mathrm{fa}$ of the Dutch Copyright Act, indicated by the "Taverne" license above, 


\title{
Collaborative learning: Elements encouraging and hindering deep approach to learning and use of elaboration strategies
}

\author{
Elda Maria Stafuzza Gonçalves Pires ${ }^{\mathrm{a}}$ (D), Durval Anibal Daniel-Filho ${ }^{\mathrm{a}}$ (D) , Jascha de Nooijer ${ }^{\mathrm{b}}$ (D) and \\ Diana H. J. M. Dolmans ${ }^{c}$ iD

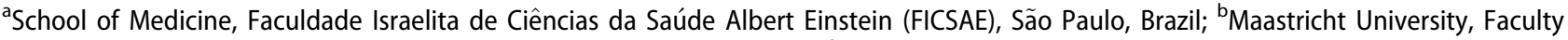 \\ of Health, Medicine and Life Sciences (FHML), Maastricht, Netherlands; 'Maastricht University, School of Health Professions Education \\ (SHE), Maastricht, Netherlands
}

\begin{abstract}
Aim: The purpose of this research was to investigate students' approaches to learning and use of cognitive strategies in a collaborative learning environment with team-based learning.

Method: In a mixed-methods study, 263 medical students from 6 different semesters answered the R-SPQ-2F Questionnaire and MSLQ's items that measure elaboration and rehearsal strategies. ANOVA was used to compare differences between semesters, and Pearson's correlation to investigate how approaches to learning, cognitive strategies, and academic achievement correlate. Focus groups elucidated which elements in the collaborative learning environment enhanced or hindered deep approach to learning or elaboration strategies and why.

Results: Students took a deep approach to learning and sometimes a surface approach. They used elaboration and rehearsal strategies. First semester's students had significantly higher deep approach than fifth and sixth semesters' students. Elaboration strategies significantly correlated with final grade. Commitment to the group, case discussions, feeling challenged by teachers, and patients' visits were perceived to enhance deep approach to learning and use of elaboration strategies, while overload in course activities hindered deep approach to learning.

Conclusions: Particular elements of the learning environment triggered students to take deep approach to learning and use elaboration strategies, and this positively correlated to academic achievement.
\end{abstract}

\section{KEYWORDS}

Collaborative/peer-to-peer; education environment; general; small group

\section{Introduction}

In the last decades, much effort has been done to improve learning environments toward a more student-centered one with the hope that they can enhance students' deep approach to learning and consequently academic achievement (Trigwell et al. 1999; Biggs et al. 2001; Dolmans et al. 2016). Since the first work of Marton and Säljö in the 1970s (Biggs et al. 2001; Baeten et al. 2010), the concept of approaches to learning has become a conceptual framework known as Students' Approaches to Learning (SAL) (Biggs et al. 2001). Students taking a deep approach to learning try to understand the learning material relate new ideas to prior knowledge, construct the meaning of the content to be learned, and critically evaluate knowledge. Students taking a surface approach mainly focus on memorizing and reproducing the learning materials, without reflecting on the processes or recognizing the wider context.

A deep approach to learning is closely related to students undertaking elaboration strategies. Elaboration strategies are for example students trying to summarize the material into their own words, relating new concepts to prior knowledge, and integrating information from different sources (Wolters et al. 2003). Elaboration can happen during self-study, discussions, note-taking or answering questions. A surface approach to learning is closely related to cognitive rehearsal

\section{Practice points}

- A collaborative learning environment with TBL is able to elicit a deep approach to learning and the use of elaboration strategies in different amounts.

- Students' approaches to learning are changeable and influenced by students' perceptions of the learning environment.

- In this context, students from the first semester took a deeper approach to learning than students from the fifth and sixth semester, due to the fact that students felt more challenged by the first semester's teacher.

- The use of elaboration strategies significantly correlated with the final grade.

- Real cases' discussions help students to structure their knowledge and motivate them towards a deep approach to learning and the use of elaboration strategies.

strategies (Wolters et al. 2003), which means that students memorize materials by repeating it over and over.

Student-centered learning environments are presumed to stimulate students to use elaboration strategies, to take

CONTACT Elda Maria Stafuzza Gonçalves Pires elda.pires@einstein.br Francisco Morato, 4293 Vila Sonia, São Paulo - SP, 05521-200, Brazil

(1) Supplemental data for this article can be accessed here.

This article has been corrected with minor changes. These changes do not impact the academic content of the article.

(C) 2020 Informa UK Limited, trading as Taylor \& Francis Group 
a deep approach to learning and foster meaningful learning. In these environments, students are motivated to be responsible for their learning, to relate new ideas to prior knowledge, to collaborate with each other in problem discussions where they have to elaborate and explain their thoughts to peers (Dolmans et al. 2005; Dolmans 2019). These learning environments are assumed to stimulate students to gain a better understanding of new concepts, in a deeper and meaningful way, integrating them to prior knowledge and being able to apply them in case discussions and problem-solving tasks.

In real life, implementing a student-centered learning environment with the purpose of fostering deep approach to learning and use of elaboration strategies is difficult because SAL and use of cognitive strategies depend on contextual factors (Biggs et al. 2001; Wolters et al. 2003; Baeten et al. 2010; Dinsmore and Alexander 2012). Appropriateness of workload, perception of the assessment, and of the quality of teaching have been shown to influence SAL (Baeten et al. 2010). How students perceive them, which can be very different from the intentions of the curriculum designer or the teachers, can also influence SAL. Besides the presence of different contextual factors, how they interplay vary in different contexts and may also influence SAL and use of cognitive strategies in distinct ways (Biggs et al. 2001; Wolters et al. 2003; Baeten et al. 2010; Dinsmore and Alexander 2012). These leads to contradictory findings across studies. Trigwell et al. (1999) found that teachers who adopt a student-centered approach may enhance a deep learning approach. But other researchers found the opposite relationship, as a student-centered environment enhanced surface approach to learning (Struyven et al. 2006).

SAL are changeable and influenced by students' perceptions of the learning environment (Trigwell and Prosser 1991; Biggs et al. 2001; Wolters et al. 2003; Baeten et al. 2010; Dolmans et al. 2016). This closely relates to the constructive alignment of the curriculum (Biggs 1996) where the objectives set by the teachers should elicit teaching methods that drive students to deep approach to learning and use of elaboration strategies, and the assessment should be aligned with these objectives and desired performances. As assessment drives learning (Van der Vleuten and Schuwirth 2005), how tests are designed can impact students' choices of cognitive strategies and how they will approach learning independently of the learning task. Previous studies showed contradictory findings between $\mathrm{SAL}$, cognitive strategies and academic achievement. Some studies did not find any correlation between SAL and academic achievement (Beckwith 1991; Gijbels et al. 2005), while others suggest that the assessment itself may drive SAL (Biggs et al. 2001). An assessment method that assesses if students are able to integrate knowledge, relate ideas, reflect and explain their reasoning, as for example a case-based assessment, will enhance students' deep approach to learning and use of cognitive strategies (Baeten et al. 2010). And when assessment encourages rote learning, memorization, and reproduction of the content, as for example multiple-choice questions aimed at recall of factual knowledge, students take a surface approach to learning, independently of the kind of learning instructions (Trigwell and Prosser 1991; Scouller 1998; Dinsmore and
Alexander 2012; Dolmans et al. 2016). This is the reason Wolters et al. (2003) claim in their paper that many studies have demonstrated that the use of rehearsal strategies is positively correlated with achievement measures. Students can get good grades and be successful in many tests just by memorizing and rehearsing the subject material, because these tests are designed to just measure recall of factual knowledge.

The approach to learning that predominates in a context can tell teachers something about the quality of the learning environment (Biggs et al. 2001). For example, if we designed a learning environment towards achieving highlevel objectives but there is a high surface approach, something is not aligned in the learning tasks or assessment methods. It also seems that depending on the learning objectives, deep and surface approaches to learning can coincide and the learner can benefit from both, while studying for the same subject (Dinsmore and Alexander 2012).

As argued by Baeten et al. (2010) in their review, SAL differ according to contextual factors and as these factors interplay differently in each learning environment, their relationship should be studied in specific contexts. What remains to be understood is which approaches to learning and cognitive strategies are used in a collaborative learning environment with team-based learning ( $T B L)$, and what aspects of the learning environment influence students to take a deep approach to learning and use elaboration strategies.

The TBL session starts with pre-class preparation. In class, it begins with readiness assurance tests to check if students studied the pre-class material and if they understood the basic concepts (factual knowledge) (Michaelsen et al. 2008). The second part of the session is for application of course concepts, when students need to explain their reasoning to peers, relate ideas, and integrate information (Reimschisel et al. 2017). The interaction in small groups and the application elements of TBL are designed to make students take a deep approach to learning and use elaboration strategies (Michaelsen et al. 2008; Reimschisel et al. 2017). However, many elements beyond the instruction design can affect students' perceptions, their approaches to learning and use of cognitive strategies. The purpose of this research was to investigate SAL and use of cognitive strategies in a context that employs collaborative learning with TBL.

This study addressed the following research questions: To which extent do students take a deep and surface approach to learning and use an elaboration and rehearsal strategy in this context? Does it differ across semesters? What is the correlation between different approaches to learning, different cognitive strategies, and academic achievement? Which elements in the collaborative learning environment enhance or hinder deep approach to learning or use of elaboration strategies and why?

\section{Methods}

\section{Design}

Using a pragmatic worldview, trying to discover what works and influences students' approach and strategies to learning in our daily practice, this mixed-methods study 
was designed with a sequential explanatory strategy. First, students rated their approaches to learning and use of cognitive strategies through a questionnaire. Later, students joined focus groups to discuss elements of the learning environment that impacted on their deep approach to learning or use of elaboration strategies.

\section{Setting}

This study was conducted from November to December 2018 at the School of Medicine of Faculdade Israelita de Ciências da Saúde Albert Einstein (FICSAE), São Paulo, Brazil. It opened in 2016, with a 6-year undergraduate medical program. At the end of December 2018, we had completed 6 semesters of implementation of the course (3 years).

At the School of Medicine of FICSAE, a flipped classroom with active learning formats is used in all sessions promoting collaborative learning. TBL is the main learning strategy. It occurs 2-3 times a week (4-6h a week). TBL begins with pre-class preparation. In class, the session starts with individual readiness assurance test (iRAT) and team readiness assurance test (tRAT), which are graded. iRAT has about 10 multiple-choice questions and is meant to check if students studied the pre-class material selected by the teacher, and if they understood the basic concepts (factual knowledge). After finishing the iRAT individually, students take the same test in group (tRAT). During tRAT, students try to explain each other their reasoning and solve any doubts they have about the concepts present in the preclass material. After iRAT and tRAT, there is a wrap-up where the teacher solves any remaining doubts and then cases discussion starts (application of concepts).

For other sessions, students have assigned readings or videos and in-class they have cases/problems discussion in small groups. In each semester, there are about 6-9 subjects occurring simultaneously, with $26 \mathrm{~h}$ per week of contact-time. Students collaborate in the same small group for all the learning activities within the different subjects for a whole semester. In total, there are 6 small groups with 6 students and 2 small groups with 7 students (50 students) in the classroom with one teacher. Groups are formed in a randomized way trying to decrease repetitions of students working together from one semester to another. Assessment of students' learning is mainly done through written tests. Teachers follow an Assessment Policy Document to develop questions to assess if students achieved high-level objectives in their subject. A group of experts evaluates the tests to guarantee that the assessment does cover the subject content well and fits with the subject objectives.

\section{Participants}

Two hundred and ninety-three medical students from the first 3 years of the program were invited to participate in the quantitative part of this study. They were studying in 6 different subjects, as they were from 6 different semesters (around 50 students in each semester, i.e. 100 per year: 1st-3rd year). Students from different semesters were invited with the intention of understanding if there was any difference in students' approach to learning and use of cognitive strategies in different semesters.
For the qualitative part, the same medical students were invited to participate in focus groups. The first researcher invited them in class, explaining the purpose of the research. There were 21 volunteers willing to share their thoughts on how the learning environment might influence their approach to learning and use of cognitive strategy. Three focus groups were scheduled at FICSAE, each one with students from 6 different semesters. Three students had personal problems on the day of the meeting, so 2 focus groups had students from 5 different semesters. Two researchers were present at each focus groups, one as a mediator (first researcher) and the other one as an observer.

\section{Quantitative data collection and analysis}

For each semester, one subject was selected, and students were invited by the first researcher to fill out a two-section online questionnaire after a TBL session (November 2018).

The first section of the questionnaire was the Revised two-factor version of the Study Process Questionnaire (RSPQ-2F) developed by Biggs et al. (2001) (Supplementary Appendix 1). It was designed to assess student's approaches to learning after a session and was validated in the Portuguese language, with nursing students from Brazil (Godoy 2009). It has 20 items and Cronbach's alpha of 0.76 for deep learning and 0.74 for surface learning (Godoy 2009). For each item, students were asked to answer on a 5-point Likert scale with anchors for each answer: (1) 'this item is never or only rarely true of me, (2) 'this item is sometimes true of me', (3) 'this item is true of me about half the time,' (4) this item is frequently true of me, (5) 'this item is always or almost always true of me.' Ten items reveal a deep approach to learning and 10 items are for the surface approach to learning. The mean score for each approach was calculated. A score below 3 means that the approach is not used half of the time, between 3 and 4 means that the approach is used more than half of the time, and above 4 means it is used most of the time.

The second section of the questionnaire had 10 items from the Motivated Strategies for Learning Questionnaire (MSLQ), that measure elaboration (6 items) and rehearsal strategies (4 items) (Wolters et al. 2003) (Supplementary Appendix 2). In previous studies Cronbach's alpha was reasonable for elaboration strategies $(0.75-0.85)$ and rehearsal strategies (0.50-0.69) (Wolters et al. 2003). These items were translated into Portuguese and validated with students in Brazil (Salvador et al. 2017). For each item, students were asked to answer on a 7-point Likert scale that ranges from (1) 'not at all true of me' to (7) 'very true of me' with no specific labels for the other response categories. The mean score for each cognitive strategy was calculated.

Academic achievement was measured through students' final grade of the subject. The final grade is mainly composed of test scores (80\%) that reflect higher-level knowledge and skills, including cases/problem-solving questions, and TBL (20\%). TBL scores consists of iRAT (20\%), tRAT (30\%) and peer evaluation (50\%). iRAT reflects recall of factual knowledge. It measures individual preparation and reflects the first part of TBL. All scores and grades range from 0 to 10 . 
Quantitative analysis was performed with IBM SPSS version 25.0 (IBM Corp., Armonk, NY). The mean scores for deep and surface learning, and for elaboration and rehearsal strategies were calculated per semester, and analysis of variance (ANOVA) was used for comparisons between the 6 semesters. To identify any relationship between scales and grades, Pearson's linear correlation coefficients were calculated.

Cronbach's alpha values for Deep and Surface Approaches were 0.77. and 0.78, respectively. For Elaboration and Rehearsal Strategies, Cronbach's alpha were 0.62 and 0.66 , respectively. McDonald's $\omega$ is also reported for each construct (Table 2 ).

\section{Qualitative data collection and analysis}

As part of the explanatory design, 1 month after answering the questionnaire, students who volunteered joined the 3 semi-structured focus groups. A discussion guide was used, starting with open-ended questions and later more specific ones that addressed the third research question of this project: which elements in the collaborative learning environment enhance or hinder deep learning or elaboration strategies and why? (Supplementary Appendix 3).

All focus groups were audiotaped, transcribed verbatim, and de-identified. Analyses of the transcripts were done by the first and second authors independently to identify frequently occurring initial codes. The analysis was conducted in an open, inductive way, trying to identify the elements and mechanisms that enhance and hinder student's deep approach to learning and use of elaboration strategies. Initial codes were consolidated, and preliminary themes developed. EMSGP kept notes with definitions and examples, and a book with detailed memos. In case of disagreements, the authors read the transcripts repeatedly, and discussions occurred until reaching an agreement. Authors went back and forth in our analysis to consolidate the themes. The third focus group did not elicit any new code, or helped in the definition of themes, reaching code and meaning saturation (Hennink et al. 2017). The final themes were debated with DHJMD.

\section{Results}

\section{Quantitative results}

Ninety percent of the students $(N=263)$ signed the Informed Consent and answered the two-section questionnaire online, after the TBL session. Table 1 shows the answer rate per class.

\section{To which extent do students take a deep and surface approach to learning and use an elaboration and rehearsal strategy in this context?}

In general, students took a deep approach to learning more than half of the time $(M=3.21$, SD 0.61) and not really seemed to take a surface approach to learning $(M=2.27$, SD 0.63) (Table 2). They used elaboration strategies $(M=5.62$, SD 0.89), and rehearsal strategies $(M=4.52$, SD 1.30). The latter seemed to differ across students given high SD. Means and SD for each construct for each semester are shown in Table 3 and Figure 1.

\section{Does it differ across semesters?}

There was a significant difference between the 6 semesters for a deep approach to learning, $F(5,257)=3.10, p=0.01$. Multiple comparisons revealed that students from the first semester had a significantly higher deep approach than sixth semester, $p=0.03$, and fifth semester, $p=0.03$. Other means were not significantly different across semesters for surface approach, elaboration, and rehearsal strategies.

\section{What is the correlation among different approaches to learning, different cognitive strategies, and academic achievement?}

Deep approach to learning significantly and positively correlated to elaboration strategies, $r=0.53,95 \% \mathrm{Cl}[0.43$, $0.61], p<0.001$, and to rehearsal strategies, $r=0.18,95 \% \mathrm{Cl}$ $[0.06,0.29], p=0.003$. Deep approach significantly and

Table 1. Answer rate per semester.

\begin{tabular}{lccc}
\hline Semester of the subject & Number of students & Answers & Answer rate (\%) \\
\hline 6th semester & 49 & 40 & 82 \\
5th semester & 45 & 41 & 91 \\
4th semester & 51 & 44 & 86 \\
3rd semester & 48 & 42 & 88 \\
2nd semester & 49 & 48 & 98 \\
1st semester & 50 & 48 & 96 \\
Total & 292 & 263 & 90 \\
\hline
\end{tabular}

Table 2. Descriptive statistics of the scales.

\begin{tabular}{lcccc}
\hline & \multicolumn{4}{c}{ Mean } \\
\hline Deep Approach & 3.21 & 0.61 & 0.77 & 0.79 \\
Surface Approach & 2.27 & 0.63 & 0.78 & 0.77 \\
Elaboration Strategies & 5.62 & 0.89 & 0.62 & 0.72 \\
Rehearsal Strategies & 4.52 & 1.30 & 0.66 & 0.68 \\
\hline
\end{tabular}

Deep and surface approach scales range from 1 to 5 . Elaboration and rehearsal strategies scales range from 1 to 7 .

Table 3. Descriptive statistics of the scales for each semester.

\begin{tabular}{lcccc}
\hline & Semester & $N$ & Mean & Standard deviation \\
\hline Deep approach & 1 & 48 & $3.46^{\mathrm{a}}$ & 0.55 \\
& 2 & 48 & 3.30 & 0.58 \\
Surface approach & 3 & 42 & 3.12 & 0.54 \\
& 4 & 44 & 3.20 & 0.73 \\
& 5 & 41 & $3.07^{\mathrm{a}}$ & 0.62 \\
Elaboration strategies & 6 & 40 & $3.06^{\mathrm{a}}$ & 0.53 \\
& 1 & 48 & 2.12 & 0.58 \\
& 2 & 48 & 2.15 & 0.67 \\
& 3 & 42 & 2.39 & 0.68 \\
& 4 & 44 & 2.28 & 0.73 \\
& 5 & 41 & 2.43 & 0.60 \\
Rehearsal strategies & 2 & 40 & 2.27 & 0.56 \\
& 2 & 48 & 5.79 & 0.70 \\
& 3 & 42 & 5.80 & 0.67 \\
& 4 & 44 & 5.38 & 0.93 \\
& 5 & 41 & 5.60 & 1.23 \\
& 1 & 40 & 5.66 & 0.97 \\
& 2 & 48 & 4.86 & 0.65 \\
& 3 & 42 & 4.80 & 1.27 \\
& 4 & 44 & 4.28 & 1.33 \\
& 5 & 41 & 4.09 & 1.16 \\
& 5 & 40 & 4.70 & 1.29 \\
& 5 & & 1.29 \\
\hline
\end{tabular}

Deep and surface approach: scales range from 1 to 5 . A score below 3 means that approach is not used half of the time, between 3 and 4 it is used more than half of the time, and above 4 it is used most of the time. Elaboration and rehearsal strategies: scales range from 1 to 7 .

aDeep approach means from 1st semester's students are significantly higher than 5th and 6th semesters' students. 


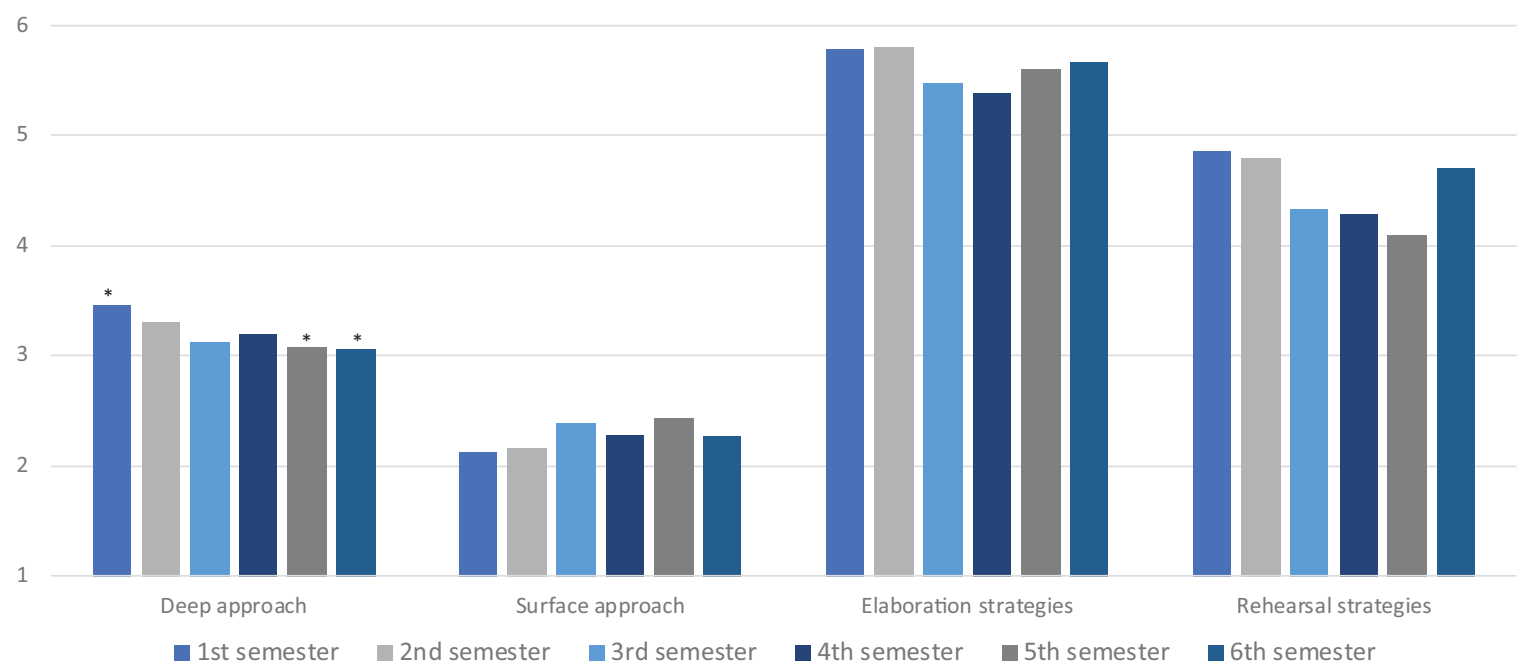

Figure 1. Constructs' means for each semester. Deep and surface approach: scales range from 1 to 5 . A score below 3 means that approach is not used half of the time, between 3 and 4 it is used more than half of the time, and above 4 it is used most of the time. Elaboration and rehearsal strategies: scales range from 1 to 7. *Deep approach means from 1st semester's students were significantly higher than 5th and 6th semesters' students.

Table 4. Pearson's correlations.

\begin{tabular}{lccc}
\hline & Deep approach & Surface approach & Elaboration strategies \\
\hline Deep approach & - & & Rehearsal strategies \\
Surface approach & $-0.52^{* * *}$ & - & - \\
Elaboration strategies & $0.53^{* * *}$ & $-0.32^{* * *}$ & $0.15^{*}$ \\
Rehearsal strategies & $0.18^{* *}$ & 0.05 & $0.28^{* * *}$ \\
iRAT & -0.05 & -0.07 & 0.05 \\
Final grade & 0.08 & $0.16^{* *}$ & 0.09 \\
\hline
\end{tabular}

$* p<0.05, * * p<0.01, * * * p<0.001$.

Table 5. Elements in the collaborative learning environment that enhance or hinder a deep approach to learning or use of elaboration strategies.

\begin{tabular}{|c|c|}
\hline & Theme \\
\hline Enhance & $\begin{array}{l}\text { Commitment to the group drives students to take a deep approach to learning } \\
\text { Students use elaboration strategies during tRAT and case discussions } \\
\text { Students try to understand the concepts in deep when feeling challenged by the teacher } \\
\text { Patients' visits provide context and framework for the diseases enhancing a deep approach to learning } \\
\text { Overload in course activities hinders deep approach to learning }\end{array}$ \\
\hline
\end{tabular}

negatively correlated to surface approach, $r=-0.52,95 \%$ $\mathrm{Cl}[-0.60,-0.43], p<0.001$. Surface approach to learning significantly and negatively correlated with elaboration strategies to learning, $r=-0.32,95 \% \mathrm{Cl}[-0.43,-0.21]$, $p<0.001$, and positively to rehearsal strategies, $r=0.15$, $95 \% \mathrm{Cl}[0.03,0.27], p=0.013$. Elaboration strategies significantly and positively correlated to rehearsal strategies, $r=0.28,95 \% \mathrm{Cl}[0.17,0.39], p<0.001$.

Elaboration strategies significantly correlated with final grade, $r=0.16,95 \% \mathrm{Cl}[0.04,0.28], p=0.009$ (Table 4). There was no significant relationship between deep approach, surface approach to learning or rehearsal strategies and academic achievement (iRAT and final grade) (all $r s<0.1$, all $p s>0.05$ ).

\section{Qualitative results}

Focus groups enlightened the findings of the quantitative part identifying which elements of the collaborative learning environment enhanced or hindered deep approach to learning or use of elaboration strategies and why. Five main themes emerged from the analysis (Table 5).

\section{Commitment to the group drives students to take a deep approach to learning}

Mainly for TBL sessions, students felt they needed to understand in depth the concepts, relate the new information to previous ones, and address knowledge gaps they perceived before class, while studying for the session. They felt committed to the group and needed to have prior knowledge for the discussions (during team readiness assurance test and cases discussions), so they could contribute to groups' learning. They acknowledged that they would learn more if they were prepared and if they knew the concepts of the topic.

\footnotetext{
My group counts on my previous preparation so we can discuss the cases. Cases are important. Because during the cases discussion is when you consolidate the learning. (P5, FG1)

I realized that if I do not study for TBL I will not learn. I will not contribute, I will be, be a burden .... (P1, FG1)
}

\section{Students use elaboration strategies during tRAT and case discussions}

Students perceived that deep learning happened in class while solving friend's doubts and discussing tRAT items 
and cases. At those times, they needed to relate the topic to previous ones and elaborate the information in their mind to be able to explain it to each other. Before an exam, they also studied in groups, testing and questioning each other. They felt they knew the topic when they felt confident to teach it to someone else.

\begin{abstract}
I think that more than learning, you have the opportunity to teach your group ... at least for me when I have the confidence to say, 'I know this, let me explain'. Wow, I don't even need to review it later, it seems I retain much more because you're not lost, you know you have mastery of that, as you are able to explain it to someone else. (P3, FG1)

But when I really learn is during cases discussions, discussing them with the group. Through cases, you have to correlate that [topic] with what you saw in other classes, you have to remember something more... surely, during cases discussions we perceive more learning. (P2, FG2)
\end{abstract}

\section{Students try to understand the concepts in deep when feeling challenged by the teacher}

Teachers were the main characters that influenced SAL. They could challenge students to take deep reasoning and promoted student's engagement to learn in deep the topic, so they came to class with enough prior knowledge to engage in deep discussions, applying the concepts in class. If teachers did not apply the knowledge in depth in class, students did not take a deep approach to learnin before class.

'If you know that the teacher will go deep enough, for example, [first-semester teacher's name], well ... he goes deep. So, you have to know, otherwise, you will get lost in class. (P6, FG1)

So, it is much about the teacher's dynamics in class. It changes a lot. It changes a lot. That's why I say that pediatrics and ObGyn are very well structured, because the teachers instigate you to think. Even if you do not like the subject, you will learn. It's always like that. It makes you attach importance to the subject. That makes you study. Say, gee, I got the topic. That's cool, even though I do not like it. (P1, FG2)

\section{Patients' visits provide context and framework for the diseases enhancing a deep approach to learning}

Contact with patients made a real difference in their learning approach. The patients helped to build a context and a framework for the diseases they needed to learn, which gave a north to students and motivated them to understand in depth the mechanisms involved in the disease, diagnosis, and treatment. Patients also helped them to relate the new knowledge to previous one and drove students to learn through curiosity and engagement to know more. They felt the need to understand in depth the concepts because they would need this information to become a physician.

When you get to see the patients ... I remember until today that I saw a case of ascites. The guy, he had ... was very characteristic, and then I remembered all the techniques of physical examination ... because whenever I thought about ascites, that patient was in my mind. And that's what I'm going to remember ... so you know umbilical hernia? I always remembered that because it was the scene that struck me. Whenever I study ascites, it was that image that came to me and I could apply all the exams, all techniques remembering it. (P3, FG1)
I need a little more of context to know where to go deeper a little bit ... with the cases, with the hospital discussion. There is a case in the hospital, you go there, it's very interesting, and you come home, and you search a book, search the internet. This, to me, makes you go deeper. And the cases of TBL, the discussion of the group, the doubts of the group. (P4, FG1)

\section{Overload in course activities hinders deep approach to learning}

Time was a crucial element that needed to be managed by them. Students felt overloaded by having assigned materials to read before all the sessions, were involved in other activities, and needed to keep their study-life balance. They needed to make choices, and these were some of the reasons for not reading all the pre-class material, especially before a non-TBL flipped classroom. It hindered their deep approach to learning because they came to some sessions without enough prior knowledge to engage in discussions.

I think that at the beginning [of the medical course] I tried to read all the assigned material before class, but with all activities that I have now, it isn't possible anymore. (P2, FG1)

If I have much time, I will read the material until I understand it. Now, if I am desperate, I say no, this is what will be assessed [in the iRAT], I will memorize it, understand? Later I will learn for the exam. Because of lack of time I have to manage things like that. (P3, FG1)

\section{Discussion}

In this collaborative learning environment with TBL, students took a deep approach to learning more than half of the time and sometimes a surface approach. They used elaboration and rehearsal strategies when studying for a TBL. Students from the first semester took a deeper approach to learning than students from the fifth and sixth semester. SAL and use of cognitive strategies did not show moderate or high correlation with academic achievement. The feeling of commitment to the group, being able to explain topics to each other during tRAT and case discussions and patients' visits were the main aspects that enhanced their deep approach to learning and use of elaboration strategies. Surface approach to learning was elicited if students did not feel challenged by the teachers, or if available time was not enough to study in depth the material.

Students did take a deep approach to learning and use elaborative strategies when studying for TBL and perceived two collaborative aspects of the learning environment that enhanced this approach and use of cognitive strategy: commitment to the group and the opportunity to explain (in their own words) concepts, ideas and their reasoning to peers. These aspects are closely related to TBL's structure that begins with preparation, and, in class, with an iRAT (recall of factual knowledge), and a tRAT, when students explain in their own words their understanding of the concepts to peers (use of elaboration strategy/deep approach to learning). TBL ends with cases discussion, when there is the application of the new knowledge, and students need to explain their reasoning to peers, relating ideas and integrating information (Reimschisel et al. 2017). Students from 
the first semester took a deeper approach to learning than students from the fifth and the sixth semester. This small difference was explained in focus groups when students acknowledged that they take a deeper approach before class when they know they will be challenged by the teacher, and they recognized the first semester's teacher as one of the most challenging ones.

Students sometimes took a surface approach to learning and used rehearsal strategies when studying for TBL. They perceived that overload in course activities and non-challenging teachers enhanced their surface approach to learning and use of rehearsal strategies, as previous studies showed (Baeten et al. 2010). Rehearsal strategies also correlated positively to deep approach to learning and elaboration strategies. This fact adds to Dinsmore and Alexander's (2012) conclusion that students use different approaches to learning, and one situation may favor one approach or both of them. The explanation for this fact may be in the structure of TBL, that starts with iRAT (recall of factual knowledge) and ends with knowledge application through cases discussions (Reimschisel et al. 2017), so both approaches to learning and cognitive strategies are useful in different moments of the TBL session.

In general, no correlation was found between SAL and cognitive strategies with academic achievement. These findings corroborate with previous studies where no strong correlations between approaches to learning and academic achievement were found (Beckwith 1991; Gijbels et al. 2005). The lack of correlation with iRAT can be explained by the lack of variation in this score. iRAT has about 10 multiple-choice questions and its objective is to check if students were prepared for the session, if they understood the basic concepts (recall of factual knowledge). As iRAT is graded, almost all students read the text before a TBL session, so iRAT scores show little variation (from 8 to 10). Only elaboration strategies correlated with final grades with a small effect size. This result may be explained by the fact that final grade reflects if students achieved highlevel objectives, solving cases and problems, and the focus groups finding where students acknowledged they studied in groups before an exam, and in these moments, they elaborated the information in their mind, and explained each other the concepts and relationships between topics using their own words.

As described by previous researches (Baeten et al. 2010; Dinsmore and Alexander 2012; Dolmans et al. 2016), how students approach to learning and use cognitive strategies depends on contextual factors that interplay in specific learning environments. This study also shows that besides factors related to collaborative learning, teachers and studyload, a new factor emerged. Patients' visits helped students to structure their knowledge and motivated them towards a deep approach to learning and use of elaboration strategies. At FICSAE, students see patients since the first semesters of the medical course, and they acknowledged that it helped them to build a framework for the diseases they have to learn. This fact relates to modern learning principles, since discussing a real patient case helps activating prior knowledge (constructive) and brings a meaningful context for the new information to be integrated (contextual process)
(Dolmans et al. 2005; Dolmans 2019), which enhance deep approach to learning.

The first strength of this study was the use of a mixedmethods design that could explain why students take one or another approach to learning or chose a cognitive strategy, according to specific aspects of the learning environment. Other strengths were the use of previously validated questionnaires and a high answer rate (90\%) of the questionnaires.

There are some limitations in this study. First, our context is very specific with TBL and flipped classroom being used all the time ( $26 \mathrm{~h}$ a week) while students work in the same small group in all sessions, for a whole semester. For these reasons, we cannot know if these results can be generalized to other collaborative contexts that have small group discussions but also lectures or other teacher-centered learning instructions. Second, we only used selfreported information from the students to measure their approach to learning and use of cognitive strategies without any other data source (e.g. as observations), or the involvement of other stakeholder (e.g. teachers), so we could not triangulate data. And third, we measured the academic achievement of TBL only through iRAT. iRAT measures previous preparation (if students read the material), does not vary much (because students come prepared for TBL), and does not measure all the deep learning and elaboration that happens during cases discussions, when students explain their reasoning to peers, relate ideas to prior knowledge and integrate information.

To enhance our understanding of how different factors affect SAL and their use of cognitive strategies, other studies in collaborative learning environments with TBL are needed. Obtaining data from multiple sources (e.g. including teachers) and with multiple methods (e.g. including observation of the learning interactions) could enhance our understanding of the relationship of different contextual factors. Another suggestion would be to add an achievement measure closely related to the learning of that TBL session.

\section{Conclusion}

This study shows that a collaborative learning environment with TBL is able to elicit a deep approach to learning and the use of elaboration and rehearsal strategies in different amounts, depending on contextual factors. The culture of commitment to the group and opportunities to explain topics to one another should be preserved in a collaborative learning environment to enhance the use of elaboration strategies, and this positively correlated to academic achievement. Teachers should realize their impact on SAL and use of cognitive strategies, as they can drive students to one way or another depending on their ability to challenge students. Contact-time and study-time should be balanced in a way that it is possible for students to take a deep approach to learning while studying for the session and come more prepared to class. 


\section{Ethical approval}

This study was submitted to the Hospital Israelita Albert Einstein Research Project Management System (Sistema de Gerenciamento de Projetos de Pesquisa - SGPP), and the Ethics and Research Committee (Comitê de Ética e Pesquisa - (EP), and was approved on 28 October 2018, under no. 3518-18. Students who accepted to participate in the research signed Informed Consent. Students who accepted to participate in the focus groups signed a second Informed Consent.

\section{Disclosure statement}

The authors report no conflicts of interest. The authors alone are responsible for the content and writing of the article.

\section{Glossary}

Team-based learning (TBL): Team-based learning is a learnercentered, instructor-directed strategy that incorporates classbased teamwork and assessment to enhance active learning and critical thinking. Originally developed by Larry Michaelsen in a business school environment to promote the benefits of small group teaching in a large group setting, it has since been increasingly used within medical education. It can be used with large or small classes and involves dividing a class into multiple small groups of between 5-7 students in a single classroom. One content-expert can instruct 20 or more teams, and grading, peer evaluation and feedback are used to promote individual and team accountability and learning. It is recommended that teams are created by the instructor with members selected on the basis of diversity of skills and other characteristics, and that members should work together in the same teams for as long as possible. The approach is characterized by three key components:

1. Individual student preparation in advance of the class Students receive a list of learning activities and a set of learning goals to be completed before the class.

2. Individual (iRATs) and Team readiness assurance tests (tRATs). A set of 10-20 multiple choice questions (MCQs) focusing on the concepts the students need to master in order to complete the next stage. This is completed individually, and then again as a team through consensus-building discussion and is followed by a clarification review by the instructor.

3. In class team application (tAPP) assignments. Students are presented with a significant problem, authentic to the type they will encounter in the workplace, which they must interpret and as a team select a specific response from a range of answers that they should also be able to explain and defend. All teams have the same problem and must make a simultaneous report of their answer.

A backward design, outcomes-based approach is recommended to ensure the focus remains on what learners should be able to do. As such, instructors should establish the situational factors and learning goals before the team application, readiness assurance tests and advance assignments. Students are graded on all stages of the work. Teams can appeal a question in the readiness assurance tests and team application if they think it is poorly written or have an alternative answer by providing an alternative question and a written, referenced argument to support their case.

Parmelee D, Michaelsen LK, Cook S, Hudes PD. 2012. Teambased learning: a practical guide: AMEE Guide No. 65. Med Teach. 34(5):e275-287.

\section{Notes on contributors}

Elda Maria Stafuzza Gonçalves Pires, MD, MHPE, is the Vice-Dean for Academic Affairs of the School of Medicine, Faculdade Israelita de Ciências da Saúde Albert Einstein (FICSAE), São Paulo, Brazil.

Durval Anibal Daniel-Filho, MD, is in charge of the Admission Office of the School of Medicine, Faculdade Israelita de Ciências da Saúde Albert Einstein (FICSAE), São Paulo, Brazil.

Jascha de Nooijer, PhD, Associate Professor, is the Director of Education for Health (Education Office), Faculty of Health, Medicine and Life Sciences (FHML), Maastricht University in the Netherlands.

Diana H. J. M. Dolmans, PhD, is a Professor at School of Health Professions Education (SHE), Maastricht University in the Netherlands. Her special interest relates to teaching and learning in innovative learning environments.

\section{ORCID}

Elda Maria Stafuzza Gonçalves Pires (iD) http://orcid.org/0000-00028792-2870

Durval Anibal Daniel-Filho (iD http://orcid.org/0000-0001-5307-8213 Jascha de Nooijer (iD http://orcid.org/0000-0003-1685-090X

Diana H. J. M. Dolmans (ID http://orcid.org/0000-0002-4802-1156

\section{References}

Baeten M, Kyndt E, Struyven K, Dochy F. 2010. Using student-centered learning environments to stimulate deep approaches to learning: factors encouraging or discouraging their effectiveness. Educ Res Rev. 5(3):243-260.

Beckwith JB. 1991. Approaches to learning, their context, and relationship to assessment performance. High Educ. 22(1):17-30.

Biggs J. 1996. Enhancing teaching through constructive alignment: thinking about teaching and learning. High Educ. 32(3):347-364.

Biggs J, Kember D, Leung DYP. 2001. The revised two-factor Study Process Questionnaire: R-SPQ-2F. Br J Educ Psychol. 71(Pt 1):133-149.

Dinsmore DL, Alexander PA. 2012. A critical discussion of deep and surface processing: what it means, how it is measured, the role of context, and model specification. Educ Psychol Rev. 24(4):499-567.

Dolmans DHJM. 2019. How theory and design-based research can mature PBL practice and research. Adv Health Sci Educ Theory Pract. 24(5):879-891.

Dolmans DHJM, De Grave W, Wolfhagen IHAP, van der Vleuten CPM. 2005. Problem-based learning: future challenges for educational practice and research. Med Educ. 39(7):732-741.

Dolmans DHJM, Loyens SMM, Marcq H, Gijbels D. 2016. Deep and surface learning in problem-based learning: a review of the literature. Adv Health Sci Educ Theory Pract. 21(5):1087-1112.

Gijbels D, Van de Watering G, Dochy F, Van den Bossche P. 2005. The relationship between students' approaches to learning and the assessment of learning outcomes. Eur J Psychol Educ. 20(4): 327-341

Godoy S. 2009. Validação para o Brasil da escala Revised two-factor Study Process Questionnaire (R-SPQ-2F) [Validation of the scale Revised two-factor Study Process Questionnaire (R-SPQ-2F) for Brazil]. http://medcontent.metapress.com/index/A65RM03P4874243N.pdf.

Hennink MM, Kaiser BN, Marconi VC. 2017. Code saturation versus meaning saturation: how many interviews are enough?. Qual Health Res. 27(4):591-608.

Michaelsen LK, Parmelee DX, McMahon KK, Levine RE. 2008. Teambased learning for health professions education - a guide to using small groups for improving learning. Sterling, VA: Ed Stylus Publishing.

Reimschisel T, Herring AL, Huang J, Minor TJ. 2017. A systematic review of the published literature on team-based learning in health professions education. Med Teach. 39(12):1227-1237.

Salvador DF, Rolando LGR, Oliveira D. d, Vasconcellos RFRR. 2017. Uso Do Questionário MSLQ Na Avaliação Da Motivação E Estratégias De Aprendizagem De Estudantes Do Ensino Médio De Biologia, Física E 
Matemática [Use of MSQL questionnaire in assessment of motivation and learning strategies of college students from biology, physics and mathematics]. Rev Educ Ciências Matemática. 7(2):56-73.

Scouller K. 1998. The influence of assessment method on students learning approaches: multiple choice question examination versus assignment essay. Higher Educ. 35(4):453-272.

Struyven K, Dochy F, Janssens S, Gielen S. 2006. On the dynamics of students' approaches to learning: the effects of the teaching/learning environment. Learn Instr. 16(4):279-294.

Trigwell K, Prosser M. 1991. Improving the quality of student learning: the influence of learning context and student approaches to learning on learning outcomes. High Educ. 22(3):251-266.
Trigwell K, Prosser M, Waterhouse F. 1999. Relations between teachers' approaches to teaching and students' approaches to learning Higher Educ. 37(1):57-70.

Van der Vleuten C, Schuwirth L. 2005. Assessment: assessing professional competence: from methods to programmes. Med Educ. 39(3): 309-317.

Wolters CA, Pintrich PR, Karabenick SA. 2003. Assessing academic selfregulated learning. In: K. A. Moore, L. H. Lippman, editors. The Search Institute series on developmentally attentive community and society. What do children need to flourish: conceptualizing and measuring indicators of positive development. New York, NY: Springer Science \& Business Media; p. 251-270. 